\title{
Accuracy of the Electronic Health Record: Patient Height
}

\author{
Matthew C Jurecki RRT, Robert L Chatburn MHHS RRT-NPS FAARC, and Madhu Sasidhar MD
}

\begin{abstract}
BACKGROUND: Protective lung ventilation requires calculating predicted body weight (BW) from height. Thus, inaccuracy of height data in the electronic health record (EHR) is a risk factor for ventilator-induced lung injury. Charted height data often have uncertain accuracy. Study purposes were (1) to evaluate the difference between patient height charted in the EHR and predicted height (PH) from ulnar length and (2) to determine how the height data source affects predicted BW and the resulting values for protective tidal volume $\left(V_{T}\right)$. METHODS: Subject height data from the EHR were collected from several ICUs. Simultaneous ulnar data were collected by measuring ulnar length $(\mathrm{cm})$ : male $\mathrm{PH}(\mathrm{cm})=79.2 \pm 3.60 \times$ ulnar length; female $\mathrm{PH}=95.6 \pm 2.77 \times$ ulnar length . For each subject, BW (kg) was calculated from height charted in EHR and from predicted height: male $\mathrm{BW}=50 \pm 0.91 \times($ height -152.4$)$; female $\mathrm{BW}=45.5 \pm 0.91 \times($ height -152.4$)$. Then $\mathrm{V}_{\mathrm{T}}$ was calculated as $8 \mathrm{~mL} / \mathrm{kg} \mathrm{BW}$. Bland-Altman analysis of height and $V_{T}$ differences (charted predicted) determined the limits of agreement. RESULTS: For white males $(n=27)$ the mean (SD) height from EHR was 177 (7.5); predicted height was 178 (6.9). The limits of agreement for height in males were -18.5 and $17.8 \mathrm{~cm}$. The limits of agreement for females were -23.1 and $21.3 \mathrm{~cm}$. The limits of agreement for $V_{T}$ in males were -1.8 and $1.8 \mathrm{~mL} / \mathrm{kg}$. The limits of agreement for $V_{T}$ in females were -3.0 and $2.9 \mathrm{~mL} / \mathrm{kg}$. CONCLUSIONS: For overall populations, mean height calculated from values charted in the EHR is similar to that estimated from ulnar length. However, for individuals, differences in height between the 2 sources can be large, leading to large differences in predicted BW and resultant $\mathbf{V}_{\mathbf{T}}$ set in terms of $\mathbf{m L} / \mathbf{k g}$. Key words: mechanical ventilation; electronic medical record; ideal body weight; predicted height. [Respir Care 2015;60(12):1715-1719. () 2015 Daedalus Enterprises]
\end{abstract}

\section{Introduction}

The current standard of care for mechanically ventilated patients includes limiting tidal volume $\left(\mathrm{V}_{\mathrm{T}}\right)$ to protect a patient's lungs from ventilator-induced lung injury (VILI). ${ }^{1}$ $\mathrm{V}_{\mathrm{T}}$ is based on predicted body weight $(\mathrm{PBW})(\mathrm{eg}$, between

The authors are affiliated with the Respiratory Institute, Cleveland Clinic, Cleveland, Ohio.

Mr Jurecki presented a version of this paper as an Editors' Choice abstract at the Open Forum of the American Association for Respiratory Care 60th International Respiratory Convention and Exhibition, held December 9-12, 2014, in Las Vegas, Nevada.

Mr Chatburn has disclosed relationships with Hamilton, Invacare, and IngMar.

Correspondence: Matthew C Jurecki RRT, Cleveland Clinic, 9500 Euclid Ave., M56, Cleveland, Ohio 44195. E-mail: jureckm@ccf.org.

DOI: $10.4187 /$ respcare.04018
6 and $8 \mathrm{~mL} / \mathrm{kg}$ PBW). But to determine PBW, we typically use prediction equations based on the patient's height. ${ }^{2,3}$ Therefore, the ability to protect the lungs ultimately depends on the accuracy of height data. Inaccurate height data can be dangerous because overestimating a person's height would lead to a $\mathrm{V}_{\mathrm{T}}$ larger than necessary, therefore increasing the risk of VILI. In fact, a recent study ${ }^{4}$ illustrated the importance of controlling $\mathrm{V}_{\mathrm{T}}$ when it found that an increase of $1 \mathrm{~mL} / \mathrm{kg}$ PBW in initial $\mathrm{V}_{\mathrm{T}}$ was associated with a $23 \%$ increase in ICU mortality risk.

Recognizing that height data charted in the patient's electronic health record (EHR) is a critical piece of patient information, we conducted an informal survey of nurses in various nursing units at the Cleveland Clinic to determine how height data are obtained upon a patient's admission. We found that height records are often based on patient self-reporting or visual estimates. However, visual estimates and even bedside tape measurements of height in ventilated patients may be inaccurate..$^{5}$ A possible alternative source of data is the height predicted by ulnar length. ${ }^{6}$ 


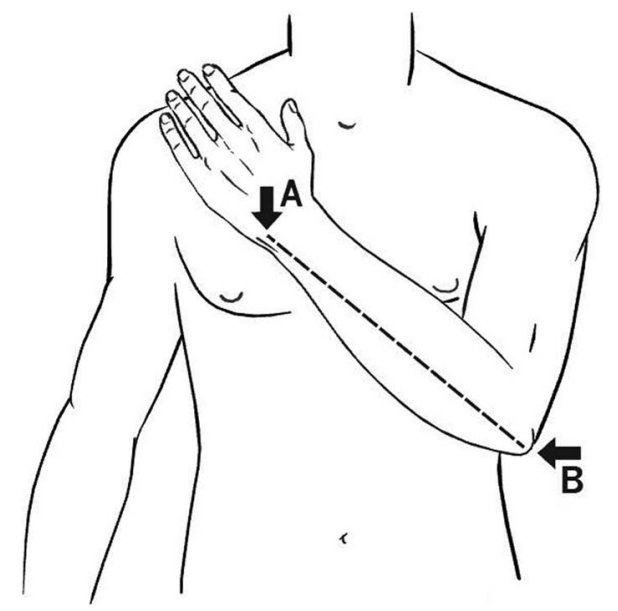

Fig. 1. Ulnar height data were collected by measuring the span between the styloid process $(A)$ and the olecranon process of the ulna (B). Courtesy the Cleveland Clinic Foundation.

The purposes of this study were (1) to evaluate the difference between patient height of unknown origin charted in the EHR and height based on ulnar length and (2) to determine the effect of the height difference in setting lung-protective $\mathrm{V}_{\mathrm{T}}$ during mechanical ventilation.

\section{See the Related Editorial on Page 1852}

\section{Methods}

The study was deemed quality improvement by our institutional review board. Subject height data were collected from the EHR for all patients from medical, neuro-, and surgical ICUs. Ulnar height data were collected by measuring the span between the styloid process and the olecranon process of the ulna (Fig. 1). An average of 3 measurements (all collected by the same person) was used in the prediction equations. Predicted height $(\mathrm{PH})^{7}(\mathrm{~cm})$ was calculated as follows: Male $\mathrm{PH}=79.2 \pm 3.60 \times$ ulnar length $(\mathrm{cm})$; Female $\mathrm{PH}=95.6 \pm 2.77 \times$ ulnar length $(\mathrm{cm})$.

For each subject, BW $(\mathrm{kg})$ was calculated from height recorded in the EHR and from the predicted height ${ }^{1}$ : Male $\mathrm{BW}=50 \pm 0.91 \times$ (height -152.4$) ;$ Female $\mathrm{BW}=45.5 \pm 0.91 \times($ height -152.4$)$.

To address the first study purpose, we evaluated the difference in height data, defined as: EHR height - ulnarbased predicted height. To address the second study purpose, we first calculated $\mathrm{BW}$ for each subject using the 2 estimates of height. We then calculated $\mathrm{V}_{\mathrm{T}}$ at $8 \mathrm{~mL} / \mathrm{kg}$ (upper end of clinically acceptable range) as a worst case scenario in terms of the risk of VILI.

\section{Data Analysis}

We used Bland-Altman analysis (corrected for small sample size ${ }^{8}$ ) to describe the differences in height and $\mathrm{V}_{\mathrm{T}}$

\section{QUICK LOOK}

\section{Current knowledge}

The current standard of care for mechanically ventilated patients includes limiting tidal volume $\left(\mathrm{V}_{\mathrm{T}}\right)$ to prevent ventilator-induced lung injury. $\mathrm{V}_{\mathrm{T}}$ is based on predicted body weight $(\mathrm{PBW})$ as determined from patient height and gender. This highlights the need for accurate height data. Inaccurate height data may lead to excessive $\mathrm{V}_{\mathrm{T}}$, increasing the risk of ventilator-induced lung injury.

\section{What this paper contributes to our knowledge}

In this study, mean height calculated from values charted in the electronic health record was similar to that estimated from ulnar length. However, for individuals, differences in height between the 2 estimates could be large, leading to large differences in PBW. These differences in PBW could in turn lead to clinically important differences in $\mathrm{V}_{\mathrm{T}}$. In the absence of accurate height measurements, the height should be based on the primary goal of patient safety during mechanical ventilation.

expected for individuals (as opposed to populations). This analysis plots the estimated "true" value as the mean of each pair of individual EHR- and ulnar-based measurements versus the difference between the two. The average difference is called the bias, and the SD of the differences is used with the bias to define the limits of agreement between the 2 measurement methods. The limits of agreement that we calculated represent the range of values within which $95 \%$ of future individual measurements will lie with $99 \%$ confidence.

\section{Results}

We did not collect enough data to include Asian $(n=1)$ or African-American males $(n=7)$ or African-American females $(n=4)$. For white males $(n=27)$, the mean (SD) height from the EHR was $177(7.5) \mathrm{cm}$. The mean predicted height (from ulnar measurement) was $178(6.9) \mathrm{cm}$. For white females $(n=24)$, the mean height from the EHR was $162(9.3) \mathrm{cm}$. The mean predicted height (from ulnar measurement) was $163(5.5) \mathrm{cm}$.

The limits of agreement for height in males were -18.5 and $17.8 \mathrm{~cm}$ (Fig. 2). The limits of agreement for females were -23.1 and $21.3 \mathrm{~cm}$ (Fig. 3). Ulnar-based height was less than charted height for 14 of 27 males (52\%) and 10 of 24 females $(42 \%)$.

The vertical axes of the Bland-Altman plots for $\mathrm{V}_{\mathrm{T}}$ are labeled in units of $\mathrm{mL} / \mathrm{kg}$ to be more clinically relevant. 


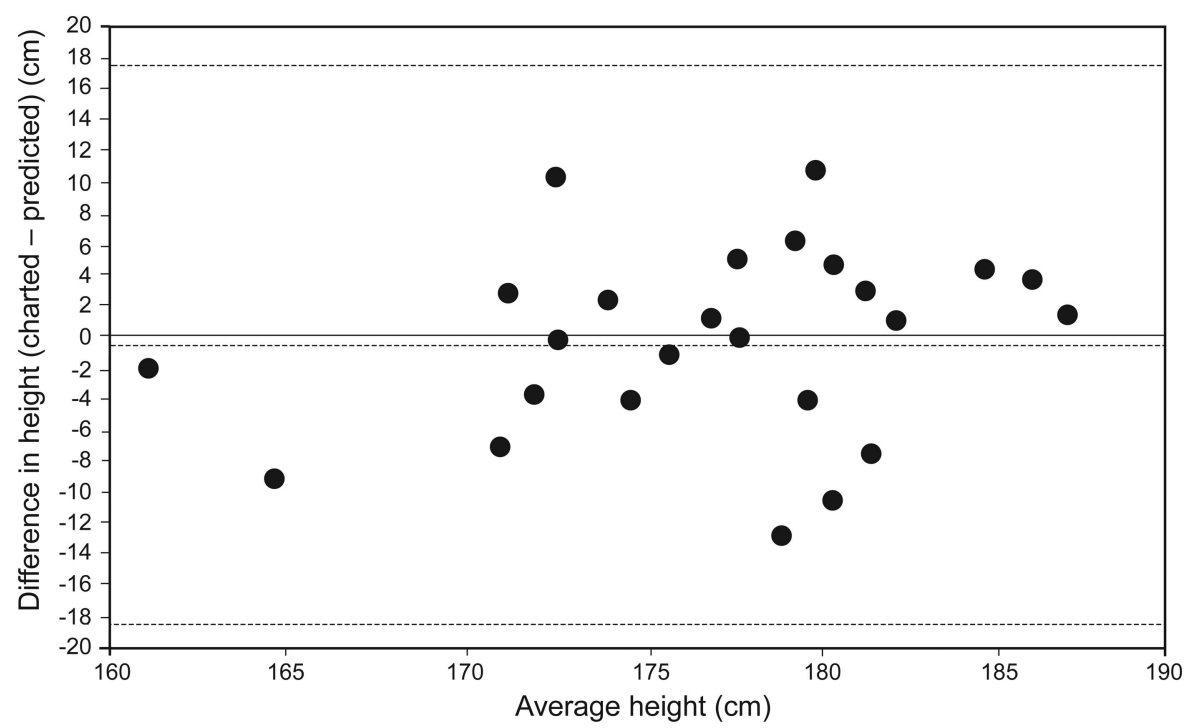

Fig. 2. Bland and Altman analysis of heights for males. Outside dashed lines denote the upper and lower limits of agreement, and the center dashed line shows the mean.



Fig. 3. Bland and Altman analysis of heights for females. Outside dashed lines denote the upper and lower limits of agreement, and the center dashed line shows the mean.

Two different axes are possible, depending on which estimate of weight is used as the reference (ie, based on charted height vs predicted height). For example, we found that in males, the mean difference was -0.07 (based on charted height) versus $-0.02 \mathrm{~mL} / \mathrm{kg}$ (based on predicted height), whereas the upper limit was 1.8 versus $1.8 \mathrm{~mL} / \mathrm{kg}$, and the lower limit was -1.9 versus $-1.8 \mathrm{~mL} / \mathrm{kg}$. For females, the mean difference was -0.2 versus $-0.1 \mathrm{~mL} / \mathrm{kg}$, the upper limit was 2.8 versus $2.9 \mathrm{~mL} / \mathrm{kg}$, and the lower limit was -3.2 versus $-3.0 \mathrm{~mL} / \mathrm{kg}$. Because these values were so close, we graphed only the values using the data based on the predicted heights (Figs. 4 and 5).
The horizontal axes for the Bland-Altman plots for $\mathrm{V}_{\mathrm{T}}$ are given in $\mathrm{mL}$ because units of $\mathrm{mL} / \mathrm{kg}$ would have yielded only 1 point (ie, the values for average $\mathrm{V}_{\mathrm{T}}$ are those calculated as $8 \mathrm{~mL} / \mathrm{kg}$ based on the 2 estimates of weight).

\section{Discussion}

The differences in mean values for height $(1 \mathrm{~cm})$ or BW $(-0.3 \mathrm{~kg})$ were clinically unimportant. This is similar to the results of Bojmehrani et al ${ }^{5}$ (visual height $=169.6 \mathrm{~cm}$, tape measure height $=169.4 \mathrm{~cm}$, ulnar-based height $=167.2 \mathrm{~cm}$ ). Their study concluded that in com- 


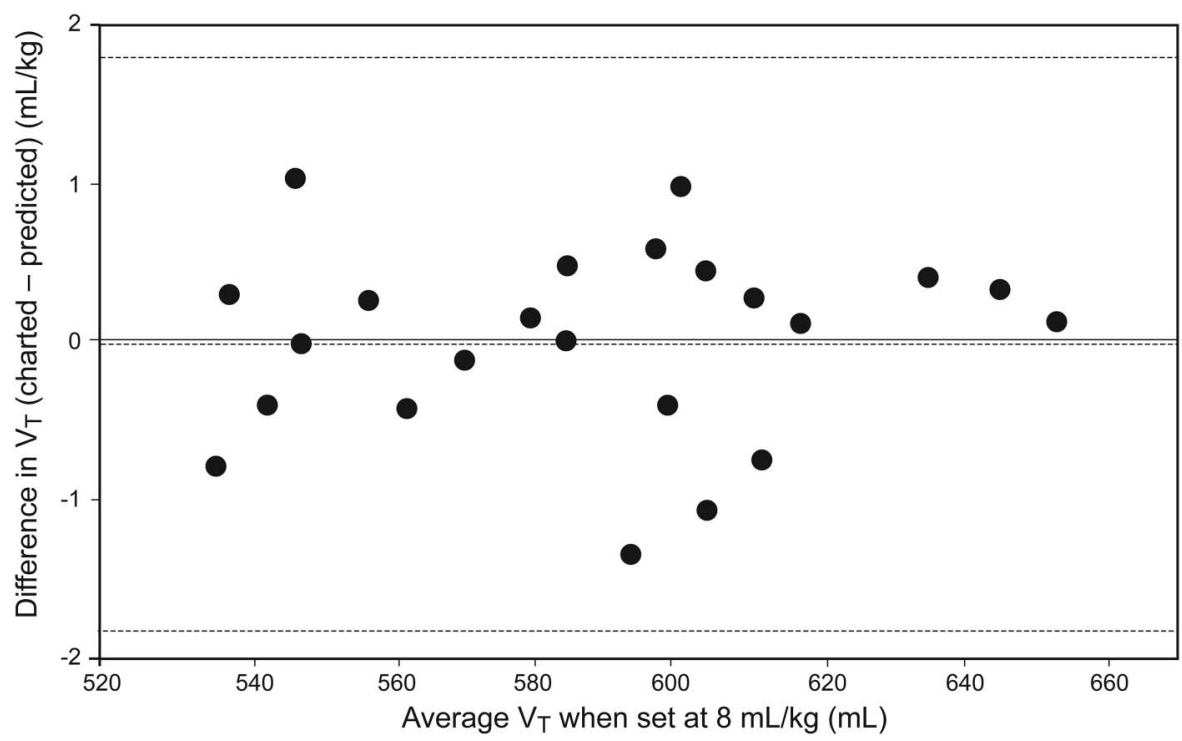

Fig. 4. Bland and Altman analysis of $V_{T}$ for males. Outside dashed lines denote the upper and lower limits of agreement, and the center dashed line shows the mean.

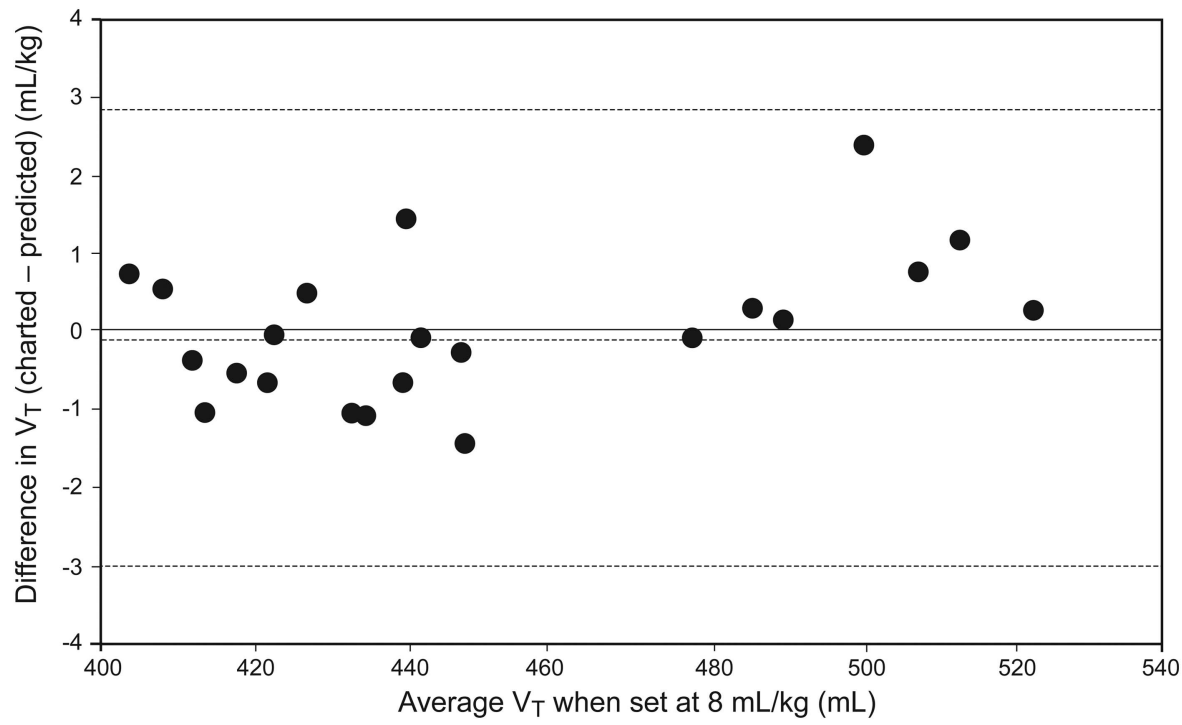

Fig. 5. Bland and Altman analysis of $\mathrm{V}_{\mathrm{T}}$ for females. Outside dashed lines denote the upper and lower limits of agreement, and the center dashed line shows the mean.

parison with the reference method, estimating the height visually and using the tape measure (potential sources of our EHR data) were less accurate than ulnar-based measurements. However, those conclusions were made for populations of subjects and did not address expected results for individuals.

When using BW to set $\mathrm{V}_{\mathrm{T}}$ (in this case at $8 \mathrm{~mL} / \mathrm{kg}$ ), we observed clinically important differences, depending on whether the weight was derived from charted height values in the EHR or from estimated height based on ulnar length. The difference in $\mathrm{V}_{\mathrm{T}}$ (EHR-based minus ulnarbased) could be about $2 \mathrm{~mL} / \mathrm{kg}$ for white males and about
$3 \mathrm{~mL} / \mathrm{kg}$ for white females (based on the limits of agreement). The problem is that the Bland-Altman analyses tell us only the potential magnitudes of expected differences, not the direction for any specific subject. For an individual patient, the most appropriate $\mathrm{V}_{\mathrm{T}}$ is based on the most accurate height. The most accurate height might be the one charted in the EHR, the one predicted from ulnar length, or some other value. This study postulates that the clinician has only 2 values for height and must decide which one to use. The uncertainty indicated by our study results is large enough to cause clinical concern. For example, if the clinician thought the $\mathrm{V}_{\mathrm{T}}$ was set at $8 \mathrm{~mL} / \mathrm{kg}$ but it was ac- 
tually 10 or $11 \mathrm{~mL} / \mathrm{kg}$, this would be a cause for concern in terms of the risk of VILI. On the other hand, if the true $\mathrm{V}_{\mathrm{T}}$ was actually 4 or $5 \mathrm{~mL} / \mathrm{kg}$, this might be a concern in terms of patient-ventilator asynchrony. ${ }^{9}$ Therefore, which height estimate to use for $\mathrm{BW}$ and setting $\mathrm{V}_{\mathrm{T}}$ would presumably be based on the primary clinical goal of mechanical ventilation (ie, safety or comfort) for a particular patient.

The major limitations of our study were the small sample size and the fact that only white males and females were included. The small sample size leads to large values for the limits of agreement. Alternative methods to obtain patients' height have been based on lower leg and ulnar measurements and are useful to facilitate lung-protective ventilation. We only studied the ulnar length method because we found more references and better operational instructions for it, and it has been referenced frequently in nutrition studies.

\section{Conclusions}

For the population of subjects in this study, mean height calculated from values charted in the EHR is similar to that estimated from ulnar length. However, for individuals, differences in height between the 2 estimates can be large, leading to large differences in BW. These differences in BW lead to clinically important differences in $\mathrm{V}_{T}$ when set in $\mathrm{mL} / \mathrm{kg}$. In the absence of known accurate height measurements, which height estimate to use for BW and setting $\mathrm{V}_{\mathrm{T}}$ should be based on the primary clinical goal of mechanical ventilation (ie, safety or comfort) for a particular patient.

\section{REFERENCES}

1. The Acute Respiratory Distress Syndrome Network. Ventilation with lower tidal volumes as compared with traditional tidal volumes for acute lung injury and the acute respiratory distress syndrome. N Engl J Med 2000;342(18):1301-1308.

2. Crapo RO, Morris AH, and Gardner RM. Reference spirometric values using techniques and equipment that meet ATS recommendations. Am Rev Respir Dis 1981;123(6):659-64.

3. Crapo RO, Morris AH, Clayton PD, and Nixon CR. Lung volumes in healthy nonsmoking adults. Bull Eur Physiopathol Respir 1982; 18(3):419-25.

4. Needham DM, Yang T, Dinglas VD, Mendez-Tellez PA, Shanholtz C, Sevransky JE, Brower RG, Pronovost PJ, Colantuoni E. Timing of low tidal volume ventilation and intensive care unit mortality in acute respiratory distress syndrome: a prospective cohort study. Am J Respir Crit Care Med 2015;191(2):177-185.

5. Bojmehrani A, Bergeron-Duchesne M, Bouchard C, Simard S, Bouchard PA, Vanderschuren A, et al. Comparison of usual and alternative methods to measure height in mechanically ventilated patients: potential impact on protective ventilation. Respir Care. 2014; 59(7):1025-1033.

6. Barbosa VM, Stratton RJ, Lafuente E, Elia M. Ulna length to predict height in English and Portuguese patient populations. Eur J Clin Nutr 2012;66(2):209-215.

7. Madden AM, Tsikoura T, Stott DJ. The estimation of body height from ulna length in healthy adults from different ethnic groups. J Hum Nutr Diet 2012;25(2):121-128.

8. Chatburn RL. Handbook for Health Care Research. Jones \& Bartlett, 2009;133.

9. Kallet RH, Campbell AR, Dicker RA, Katz JA, Mackersie RC. Effects of tidal volume on work of breathing during lung-protective ventilation in patients with acute lung injury and acute respiratory distress syndrome. Crit Care Med 2006;34(1):8-14.

This article is approved for Continuing Respiratory Care Education credit. For information and to obtain your CRCE

(free to AARC members) visit

www.rcjournal.com

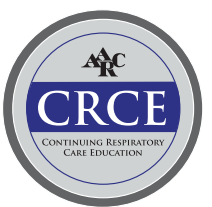

